\title{
Tau pathology: predictive diagnostics, targeted preventive and personalized medicine and application of advanced research in medical practice
}

\author{
Illana Gozes
}

Received: 6 May 2010/Accepted: 25 May 2010 / Published online: 12 June 2010

(C) European Association for Predictive, Preventive and Personalised Medicine 2010

\begin{abstract}
Microtubules are key cytoskeletal elements found in all eukaryotic cells. The microtubule shaft is composed of the heterodimer protein, tubulin and decorated with multiple microtubule associated protein, regulating microtubule function. Tau (tubulin associated unit) or MAPT (microtubule associated protein tau), among the first microtubule associated proteins to be identified, was implicated in microtubule initiation as well as assembly, with increased expression in neurons and specific association with axonal microtubules. Alzheimer's disease (AD) is the most prevalent tauopathy, exhibiting tau-neurofibrillary tangles associated with cognitive dysfunction. AD is also characterized by $\beta$-amyloid plaques. An abundance of tau inclusions, in the absence of $\beta$-amyloid deposits, can be found in Pick's disease, progressive supranuclear palsy (PSP), corticobasal degeneration (CBD) and other diseases, collectively described as tauopathies. The increase in tau pathology in $\mathrm{AD}$ correlates with the associated cognitive decline. The current manuscript touches on the variability as well as common denominators of the various tau pathologies coupled to new approaches/current innovation in treatment of tauopathies in favor of advanced technologies in predictive diagnostics, targeted preventive and personalized medicine (PPPM).
\end{abstract}

Keywords PPPM · Tauopathy · Tau · MAPT · Alzheimer's disease $\cdot$ Frontotemporal dementia

I. Gozes $(\bowtie)$

Department of Human Molecular Genetics and Biochemistry

The Lily and Avraham Gildor Chair for the Investigation of Growth Factors and The Adams Super Center for Brain Studies Sackler Faculty of Medicine,

Tel Aviv University,

Tel Aviv 69978, Israel

e-mail: igozes@post.tau.ac.il

\section{Tau background}

The understanding of the multiple triggers of neurodegeneration is bound to lead to better diagnostics and improved therapeutics. In this respect and looking for unifying pathways, the accumulation of intracellular neurofibrillary lesions composed of abnormally phosphorylated and aggregated tau protein was identified as characteristic in many neurodegenerative disorders [1].

The microheterogeneity of tubulin $[2,3]$, the building block of the microtubule shaft, expressing multiple isotypes with brain specificity [4], coupled to the intricate complexity of the microtubule interacting proteins leads to enhanced control of neuronal function. Mis-metabolism and mutations in tubulin or in the interacting proteins leads to a variety of disease conditions, e.g. [5]. Here the emphasis will be put on the tubulin interacting protein, tau.

Tau (tubulin associated unit) or MAPT (microtubule associated protein tau) [6] is required for microtubule initiation as well as assembly [7], with increased expression in neurons and specific association with axonal microtubules [8]. MAPs binding to tubulin/microtubules enables them to play a fundamental role in promoting microtubule assembly and stability $[6,9,10]$. Functionally, microtubules are essential for cell division, neuronal development, maintenance of neuronal shape, neuronal plasticity (e.g. plasticity of dendritic spines and axoplasmic transport with tau participating in neurite extension and axonal transport [11-14].

Tau is primarily a neuronal protein, though not exclusively. In an adult human brain, there are six major isoforms of tau derived from a single gene through alternative splicing $[15,16]$. These isoforms differ by the presence or absence of one or two short inserts in the amino terminal half and in whether they contain three or four tubulin binding domain repeats in the carboxy terminal 
half. The alternative splicing of tau has been suggested to impact axonal functional homeostasis [17], and 3 repeat tau was suggested to have a stronger effect on axon transport dynamics.

Using cultured Aplysia neurons and online confocal imaging of human tau, it was shown that over-expression of tau generates the hallmarks of human tau pathogenesis. It was further demonstrated that the tau-induced impairment of organelle transport is because of polar reorientation of the microtubules along the axon or their displacement to submembrane domains establishing that tau overexpression leads to impaired retrograde and anterograde organelle transport [18].

The following review is an update on a review in press in Current Alzheimer Research [19] it is not a comprehensive review of the literature, but rather a point of view touching upon some recent publications as follows below.

\section{Tauopathies}

Disruption of the microtubule network is a hallmark of neurodegeneration, including the most prevalent tauopathy, Alzheimer's disease (AD). AD is characterized by the deposition of intracellular fibrillar structures forming paired helical filaments (PHFs) followed by larger aggregates termed neurofibrillary tangles (NFTs) [20] as well as the $\beta$ amyloid deposits.

Tau was originally identified as the primary component of PHF [21-27]. NFTs are composed mainly of PHFs with a minority of straight filament (SF), [28-30]. PHFs appear to consist of two filaments that are wound helically around one another, with a longitudinal spacing between crossovers of about $80 \mathrm{~nm}$ and a width of $30 \mathrm{~nm}$ at the widest point and $15 \mathrm{~nm}$ at the narrowest [31]. PHFs morphology distinguishes them from microtubules (250 $\mathrm{nm}$ diameter), neurofilaments $(\sim 100 \mathrm{~nm}$ diameter $)$ and microfilaments ( $\sim 60 \mathrm{~nm}$ diameter) which are the major cytoskeletal elements in healthy neurons [28-30,32]. The biochemistry of tau is a subject of multiple reviews [33].

Phosphorylation occurs on a number of different parts of tau and an increase in phosphorylation generally reduces tau-tubulin binding. A link to a slide delineating different tau domains and tau mutations can be accessed via: http://www.alzforum.org/res/com/mut/tau/table1.asp. This site outlines the various mutations that have been found in tau that are associated with multiple tauopathies including $\mathrm{CBD}=$ corticobasal degeneration. DDPAC $=$ disinhibition-dementia-parkinsonism-amyotrophy complex; FTD $=$ frontotemporal dementia. FTDP-17 = FTD with Parkinsonism linked to chromosome 17; HFDT = hereditary frontotemporal dementia; MSTD = multiple system tauopathy dementia; PPND = pallidopontonigral dementia; and PSP = progressive supranuclear palsy. The different tau mutations are associated with different morphology of the tau pathology (http://www.alzforum. org/res/com/mut/tau/table1.asp). The original identification of mutations in tau in familial forms of FTD was described in 1998 [34-37].

The majority of tau in PHFs and NFTs is hyperphosphorylated [38, 39]. This hyperphosphorylation maybe related to either an increase in kinase activity or a decrease in phosphatase activity [40]. Additionally, tau undergoes a specific type of serine-threonine O-glycosylation, and these modifications can reduce the extent of tau phosphorylation [41]. Tau can also be tyrosine phosphorylated [42], sumoylated and nitrated [43], although the effects of these modifications on tau require further investigations. Tau hyperphosphorylation appears to precede its accumulation in the affected neurons in $\mathrm{AD}[44,45]$. Hyperphosphorylated tau shows impaired axonal transport [12, 46], defective microtubule binding [47-50], failure to promote microtubule assembly [51, 52], and self-assembly into NFTs [53, 54]. Additionally, hyperphosphorylation of tau might make it more resistant to caspase proteolysis as well as degradation and thereby more likely to accumulate in neurons, forming PHFs and NFTs [55].

As suggested above, original studies indicated that a down-regulation of protein phosphatase 2A (PP2A), the major tau phosphatase in human brain, contributes to tau hyperphosphorylation in AD. Importantly, PP2A dephosphorylated tau at several phosphorylation sites with different efficiencies. Among the sites studied, Thr205, Thr212, Ser214, and Ser262 were the most favorable sites, and Ser199 and Ser404 were the least favorable sites for PP2A in vitro. In addition to its direct effect on tau, inhibition of PP2A with okadaic acid in metabolically active rat brain slices caused inhibition of glycogen synthase kinase-3beta (GSK-3beta) via an increase in its phosphorylation at Ser9. GSK-3beta phosphorylates tau at many sites, with Ser199, Thr205, and Ser396 being the most favorable sites. The overall alterations in tau phosphorylation induced by PP2A inhibition were the result of the combined effects of both reduced tau dephosphorylation due to PP2A inhibition directly and reduced phosphorylation by GSK-3beta due to its inhibition [56]. Tau phosphorylation impacts its biological activity and neurofibrillary degeneration in association with the specific phosphorylation site (for a comprehensive web site on tau hyperphosphorylation, including the kinases involved see (http://www.alzheimer-adna.com/Gb/Tau/ TauPhosphoSeq.htm). Thus, the interplay between phosphorylating enzymes and phosphatases plays a role in tauopathy progression. 
Most of the tau phosphorylation sites that have been characterized were Ser and Thr residues. More recent reports showed that tau can be phosphorylated at Tyr residues by kinases including Fyn, Syk, and c-abl (Abl). Proteomic analyses show that tau phosphorylated at Tyr394 (Y394) exists within AD PHF samples. It was further shown that Abl phosphorylated this particular site on tau. A most recent report showed that Arg, the other member of the Abl family of tyrosine kinases, also phosphorylates tau at Y394 in a manner independent of Abl activity. Given the reported role of Arg in oxidative stress response and neural development, the ability to phosphorylate tau at Y394 implicated Arg as a potential player in the pathogenesis of $\mathrm{AD}$ and other tauopathies [57].

The MAPT gene on human chromosome 17 appears in two main extended haplotypes. In a total of approximately 200 unrelated Caucasian individuals, there was complete disequilibrium between polymorphisms which span the gene (which covers approximately $100 \mathrm{~kb}$ of DNA). This showed an establishment of the two haplotypes (H1 and H2) [58]. It was further shown that the more common haplotype (H1) is significantly over-represented in PSP patients [59].

Single nucleotide polymorphisms mapped linkage disequilibrium in the regions flanking MAPT and have established the maximum extent $(\sim 2 \mathrm{Mb})$ of the haplotype block on chromosome $17 \mathrm{q} 21.31$ [60] and a $900 \mathrm{~kb}$ inversion which suppresses recombination [61]. This $\sim 2 \mathrm{Mb}$ gene-rich region extends centromerically slightly beyond $(\sim 400 \mathrm{~kb})$ the corticotrophin releasing hormone receptor 1 gene. The telomeric end was defined by a $\sim 150 \mathrm{~kb}$ region beyond the WNT3 gene. This study of Pittman et al., showed that the entire H1 haplotype is associated with PSP, which may implicate several other genes in addition to MAPT, as candidate pathogenic loci [60]. Additional studies by Pittman et al., resolved multiple variants of the $\mathrm{H} 1$ haplotype, reflecting a greater diversity of MAPT than can be explained by the $\mathrm{H} 1$ and $\mathrm{H} 2$ clades alone [62].

Mild cognitive impairment (MCI) is often considered a transitional condition prodromal to AD. Therefore, the genotypes of 7 polymorphisms tagging the major tau haplotypes were assayed on 186 patients with amnestic MCI and 191 unrelated controls. Association study was conducted by logistic regression including apoliprotein $\mathrm{E}$ genotype and age as covariates (with the aplipoprotein E4 and age representing major risk factors for $\mathrm{AD}$ ). The common $\mathrm{H} 1$ haplotype was found to be significantly overrepresented in amnestic MCI patients. This finding was confirmed when the aplipoprotein E4 allele was taken into account. These results suggest 1] that the risk of MCI is influenced by tau protein gene variations and 2] that MCI shares a common genetic background with $\mathrm{AD}$. The results may help elucidating the genetic risk to cognitive decline and designing effective clinical trials, future diagnostics and future therapies [63].

Interestingly, in trying to evaluate the rate of progression and the predictors of worsening in frontotemporal lobar degeneration (FTLD) patients, 127 FTLD patients entered a study and were re-evaluated at 1-year follow-up. A statistical driven approach on wide neuropsychological, behavioral, and functional data was applied to identify homogeneous groups both at baseline and at follow-up within FTLD, taking into account: (i) the demographic characteristics, (ii) the genetic background, i.e. apolipoprotein E genotype, tau haplotype, and functional polymorphisms affecting serotonin and dopamine pathways, and (iii) the clinical phenotype. On the basis of the overall assessment (disease severity), the results recognized two groups of patients, "good performers" and "bad performers". At 1-year follow-up, almost $30 \%$ of FTLD patients progressed from "good" to "bad" performances, whilst 70\% maintained stable "good" performances. Apolipoprotein E4 allele, Tau H2 haplotype and behavioral variant FTD phenotype were associated with worse prognosis over time, suggesting specific genetic and clinical predictors in FTLD progression [64] that converge and differ from those of other tauopathies (e.g. amnestic MCI/AD and PSP).

Recent reviews describe the different tauopathies, e.g. $[33,65]$. Thus, tau comprises the Pick bodies found in Pick's disease (PiD) with aggregates of three microtubule binding repeat tau (3R tau) and frontal atrophy associated with cognitive clinical dysfunction of frontal dysexcutive syndrome, progressive nonfluent aphasia and semantic dementia [33, 65].

Like other tauopathies, progressive supranuclear palsy (PSP) is characterized by accumulation of abnormally phosphorylated tau [66, 67]. Predominantly, the four microtubule binding domain (4R) form of tau accumulates in straight NFTs in neurons and glial cells in affected brain regions $[59,67,68]$. PSP is characterized by NFTs in basal ganglia, diencephalon, and brain stem with frontal executive cognitive impairment and movement disorders characterized by supranuclear gaze palsy, falls and Parkinsonism-like behavior [65, 69-71]. It is a rare progressive disease [7274]. Like in $\mathrm{AD}$ and $\mathrm{PiD}$, brain atrophy occurs in patients with PSP. While some degree of brain atrophy occurs with normal aging, the atrophy in PSP is more pronounced [75, 76], correlating with clinical disease progression [77] and assessed by structural brain imaging [75, 78].

Cortico-basal ganglionic degeneration (CBD) is characterized by parietofrontal or frontotemporal atrophy and pallor in substantia nigra and 4R tau-aggregates (also found in glial lesions) that is manifested by cognitive dysfunction - 
cortical sensory loss, apraxia (loss of the ability to execute or carry out learned purposeful movements) and asymmetric akinetic rigid syndrome $[33,65]$.

PiD, PSP and CBD are subtypes within the broader category of called frontotemporal dementias (FTD). Another FTD is frontotemporal dementia with Parkinsonism linked to chromosome 17 (FTDP-17) that is characterized by frontal atrophy often seen with tau-positive neuronal and glial inclusions with behavioral changes, cognitive decline and Parkinsonism [34].

Many of the tau alterations that are characteristic of $\mathrm{AD}$ have also been identified in PSP and CBD. Tau truncation at Asp421 is an alteration that is unique to neuronal lesions, occurring in Pick bodies as well as in NFTs, but not in lesions associated with glia. Conversely, phosphorylation at Ser422 is not only present in all these lesions, but identifies additional glial and neuronal pathology in diseasesusceptible cortical regions. The results suggest that the molecular alterations of tau that occur during the initial process of tangle formation in $\mathrm{AD}$ are similar in non- $\mathrm{AD}$ tauopathies, but the middle and later changes are not common to all diseases [79].

Tauopathies include also the early-onset dementia observed in Down syndrome (DS; trisomy 21). Splicing misregulation of adult-specific exon 10 results in expression of abnormal ratios of tau isoforms, leading to FTDP. Positions +3 to +19 of the intron downstream of exon 10 define a hotspot: Point mutations in it result in tauopathies. All these mutations increase the inclusion of exon 10 except for mutation +19 , which almost entirely excludes exon 10. To investigate the tau connection between DS and $\mathrm{AD}$, a recent study examined splicing factors located on chromosome 21 for their effect on tau exon 10. In these experiments, the splicing factor located on chromosome 21, heterogeneous nuclear ribonucleoprotein E3 - hnRNPE3 (PCBP3), was found to modestly activate the splicing of exon 10 by interacting with its proximal downstream intron around position +19 [80]. Other studies found decreased levels of Tra2beta, an RNA splicing factor responsible for tau exon 10 inclusion, in both cortical cell cultures exposed to MG132 (proteasome inhibitor) and in cerebral cortex after ischemic injury, suggesting that transient focal cerebral ischemia reduces tau exon 10 splicing through a mechanism involving proteasome-ubiquitin dysfunction and down-regulation of Tra2beta [81].

\section{Diagnostic tools}

Cerebrospinal fluid (CSF) total tau levels vary widely in neurodegenerative disorders, thus not being useful in their discrimination over AD. It has been suggested that total tau alongside with amyloid beta can predict conversion from $\mathrm{MCI}$ to $\mathrm{AD}$ [82-85]. AD is characterized by a signature of phosphorylated tau and amyloid beta in the CSF [84], coupled with brain imaging technologies this can follow $\mathrm{AD}$ disease progression [86-88] (http://www.labtestsonline. org/understanding/analytes/tau/test.html). Commercial companies like Applied NeuroSolutions, Inc. (http://www. appliedneurosolutions.com/) and Innogenetics (http://www. innogenetics.com/neurodegeneration.html) offer measurements of phosphorylated tau in the CSF, specifically P-tau 231 and P-tau 181 determination, respectively. Furthermore, a novel strategy to characterize tau versions present in CSF with respect to their molecular mass and isoelectric point was just published which will facilitate advanced diagnosis [89].

A recent study characterized and measured tau forms in order to verify the differential patterns among neurodegenerative disorders. A quantitative immunoprecipitation was developed showing an extended $(55 \mathrm{kDa})$, and a truncated (33 kDa) forms of tau in the CSF with differential expression. Thus the tau ratio $33 \mathrm{kDa} / 55 \mathrm{kDa}$ was significantly decreased in patients with PSP $(0.46+/-0.16)$ when compared to controls, including healthy subjects $(1.16+/-0.46, P=0.002)$ and $\mathrm{AD}(1.38+/-0.68, P<0.001)$, and when compared to FTD $(0.98+/-0.30, P=0.008)$ or CBD $(0.98+/-0.48$, $P=0.02)$. Moreover, in PSP patients tau form ratio was lower than in other neurodegenerative extrapyramidal disorders, such as Parkinson disease $(1.16+/-0.26, P=0.002)$ and dementia with Lewy bodies $(1.44+/-0.48, P<0.001)$. Tau ratio $33 \mathrm{kDa} / 55 \mathrm{kDa}$ did not correlate either with demographic characteristics, cognitive performances or with motor impairment severity. Truncated Tau production shows a different pattern in PSP compared to other neurodegenerative disorders, supporting the view of disease-specific pathological pathways. These findings are promising in suggesting the identification of a marker for PSP diagnosis in clinical practice [90].

Another study suggested that CSF concentrations of the 42 amino acid fragment of amyloid-beta (Abeta42), neurofilament light chain (NFL), neurofilament heavy chain (pNFH), tau protein, glial fibrillary acidic protein (GFAP), neuron specific enolase (NSE), S-100B protein, and myelin basic protein (MBP) that are released into the CSF after brain tissue damage caused by a variety of neurological diseases could be of value in the differential diagnosis of neurodegenerative disorders [91].

In an elegant study 18 signaling proteins in blood plasma were suggested to be used to classify blinded samples from $\mathrm{AD}$ and control subjects with close to $90 \%$ accuracy and to identify patients who had MCI that progressed to AD 26 years later. Biological analysis of the 18 proteins points to systemic dysregulation of hematopoiesis, immune 
responses, apoptosis and neuronal support in presymptomatic AD. Further studies should evaluate whether this test could be implemented for other tauopathies and whether distinction can be made based on this highly desirable plasma evaluation tool [92].

A recent study also used a molecular imaging probe for plaques and tangles, 2-(1-\{6-[(2-[F-18]fluoroethyl)(methyl) amino]-2-naphthyl ethylidene)malonon itrile ([(18)F] FDDNP) relating cognitive ability to positron emission tomography (PET) and suggesting this an a potential early diagnostic tool [93].

Tau as a drug target is a relatively young field and future clinical studies should aim at evaluating tau distribution in biological fluids as well as develop imaging technologies to identify potential changes in tau following candidate drug application.

\section{Activity-dependent neuroprotective protein (ADNP), tauopathy and neuroprotection}

Our own focused research is on activity-dependent neuroprtective protein (ADNP). When we discovered ADNP [94, 95] and as I have recently reviewed [96], bioinformatics suggested that ADNP is a transcription factor containing a homeobox domain profile with sequence motifs that are associated with nuclear localization as well as cellular secretion and uptake. These structural characteristics imply nuclear, cytoplasmic and extracellular functions [94, 95]. When we performed complete knockout of ADNP in the mouse, our results revealed cranial neural tube closure failure and death on E8.5-9.0 of the ADNP-knockout embryos [97]. To further elucidate ADNP associated pathways, we used Affymetrix microarrays on ADNP knockout and control mouse embryos (E9), resulting in gene expression changes of $>450$ genes. A group of dramatically up-regulated gene transcripts in the ADNP-deficient embryos were clustered into a family encoding for proteins enriched in the visceral endoderm such as apolipoproteins (including apolipoprotein E), cathepsins and methallotionins. A down regulated gene cluster associated with ADNP-deficiency in the developing embryo consisted of organogenesis markers including neurogenesis (Ngfr, neurogenin1, neurod1) and heart development (Myl2) [98]. Our results placed ADNP at a crucial point of gene regulation, repressing potential endoderm genes and enhancing genes associated with organogenesis/neurogenesis. Immunoprecipitation experiments showed interactions with heterochromatin protein $1 \alpha(\mathrm{HP} 1 \alpha)$ [98] and with BRG1, BAF250a, and BAF170, all components of the SWI/SNF (mating type switching/sucrose nonfermenting) chromatin remodeling complex [99]. Together, our results place
ADNP in a chromatin remodeling epigenetic role in neurodifferentiation and neuroplasticity and aging.

While complete ADNP-deficiency is lethal, we have shown that ADNP heterozygous mice $(+/-)$ survive, but exhibit phenotypic deficiencies. ADNP $+/-$ male mice exhibited cognitive deficits, significant increases in phosphorylated tau, tangle-like structures emanating from astrocytes (as described for CBD and PSP) and neurodegeneration as compared to ADNP+/+ mice [100]. It is an open question as to whether ADNP is directly associated with human tauopathies.

Interestingly, comparison of the expression of ADNP mRNA in the peripheral blood mononuclear cells (PBMCs, i.e. T-cells, B-cells, monocytes and natural killer cells) of normal subjects and multiple sclerosis patients showed that monocytes, B-cells and T-cells, but not regulatory (CD4 + $\mathrm{CD} 25+)$ T-cells expressed ADNP that was reduced in the PBMCs of multiple sclerosis patients compared to those of the healthy controls. The authors suggested that the decreased expression of ADNP in PBMCs of multiple sclerosis may contribute to reduced immuno-regulatory capacity in these patients [101]. Other studies showed increased tau hyperphosphorylation in multiple sclerosis [102].

\section{Drug candidates aimed at tauopathy $[19,103-105]$}

Several aspects of tauopathy are currently targeted. Those include, targeting tangles to break the potentially toxic aggregates, inhibiting tau phosphorylation, accelerating tau dephosphorylation, and accelerating — tau microtubule interactions (for review please see [106]).

Advanced models of tauopathy have been developed for translational research, including a model for rapid analysis of tau-related degeneration in zebrafish [107], a model of tauopathy in drosophila that dissociates tau toxicity and phosphorylation at the level of GSK-3beta, MARK and Cdk5. The model suggests that, in addition to tau phosphorylation, microtubule binding plays a crucial role in the regulation of tau toxicity when misexpressed. These data have important implications for the understanding and interpretation of animal models of tauopathy [108]. Advanced mouse models are many as recently reviewed [109]. Preferred models include models where the transgene can be inactivated at will (e.g. [110]). Interestingly, the propagation of protein misfolding, such as tau, may occur through mechanisms similar to those that underlie prion pathogenesis [111-113].

Non-related studies have shown tau enrichment in metastatic tumors and an ability of tau to promote tumor cell reattachment through tubulin microtentacles formation, 
supporting a model in which tau-induced microtubule stabilization provides a selective advantage during tumor metastasis [114] and suggesting a potential cross talk between cancer therapeutics/diagnosis and tauopathies.

Our research demonstrated that an 8-amino-acid peptide fragment of ADNP was capable of conferring neuroprotection. This peptide fragment is called davunetide (also known as NAP) and has the following amino acid sequence:

$$
\begin{aligned}
& \mathrm{H}_{2} \mathrm{~N}-\mathrm{Asn}-\mathrm{Ala}-\mathrm{Pro}-\mathrm{Val}-\mathrm{Ser}-\mathrm{Ile}-\mathrm{Pro}-\mathrm{Gln} \\
& \quad-\mathrm{COOH}
\end{aligned}
$$

Preclinical experiments indicate that davunetide has neuroprotective, cognitive protective, and neurotrophic properties. Importantly, NAP (davunetide), did not affect dividing cells (unlike paclitaxel and other microtubule targeting drugs) [115].

We have indentified NAP (davunetide) as a potent neuroprotectant in a wide range of in vitro models [116] against a number of toxic insults including several relevant to neurodegenerative diseases such as amyloid beta peptide [94, 117], excitotoxicity [94], oxidative stress [118] and oxygen glucose deprivation associated apoptosis [119]. We have further identified NAP (davunetide) as a neurotrophic factor, stimulating neurite outgrowth and synapse formation [120]. These results were corroborated by other investigators worldwide [121-123].

To understand the biological significance of NAP (davunetide) activity, we have generated mice partially deficient of the NAP (davunetide) -containing protein, ADNP [100]. As indicated above, while the complete knockout embryos do not form a brain and die in utero [97, 99], the heterozygous mice live and exhibit severe learning deficiencies which are ameliorated, in part, by intranasal NAP (davunetide) treatment [100]. Tau hyperphosphorylation occurs in these ADNP deficient mice and is reduced by NAP (davunetide) treatment [100]. These studies demonstrate the functionally significant role of ADNP and NAP (davunetide) in limiting tau hyperphosphorylation.

As indicated above, multiple sclerosis may also be associated with tauopathy [102] and recent studies associated reduced ADNP in the altered immune capacity of the patients which maybe compensated by NAP (davunetide) treatment [101, 124].

We have further shown activity for NAP (davunetide) in a number of transgenic mouse models of dementia including $\mathrm{AD}$ and tau mutations. In one of our most recent studies, chronic intranasal NAP (davunetide) treatment has been shown to reduce neurofibrillary tangles and tau hyperphosphorylation in a "pure" tauopathy model that has direct relevance of FTD [125]. This double transgenic mouse model developed by our collaborator Dr. Rosenmann at Hadassah Hospital in Israel has two mutant tau transgenes
(P301S; K257T) under the control of the tau promoter [126]. The mice develop inclusions in the hippocampus and cortex accompanied by cognitive and behavioral dysfunction. These mutations (reviewed in [127]) are both known to cause familial forms of FTD with variable features of PSP, CBD and less frequently amyotrophy, due to the tau proteins having a reduced ability to stabilize microtubules. We treated the tau transgenic mice with intranasal NAP (davunetide) over several months which resulted in reduced tau phosphorylation and tangle pathology paralleled with improved short-term spatial learning and memory [125]. Our results indicate that long-term NAP (davunetide) treatment associated with reduction in tau pathology may improve cognitive function and slow disease progression.

The triple transgenic mouse model of $\mathrm{AD}$ expressing mutant APP (Swedish), tau (P301L), and presenilin-1 (M146V) develops both neurofibrillary tangles and amyloid beta plaques in a progressive fashion [128]. When we treated 12-month-old animals with an intranasal dose of $2 \mu \mathrm{g} /$ day $(\sim 0.07 \mathrm{mg} / \mathrm{kg} /$ day $)$ for 3 months our results showed a $70 \%$ decrease in phosphorylated tau at Ser202/ Thr205, Thr231, and Ser202 residues [129, 130]. Histological examination of the hippocampal CA1 region confirmed that NAP (davunetide) treatment resulted in a reduction of phosphorylated tau. Treatment of 9-month-old animals with an intranasal dose of $0.5 \mu \mathrm{g} /$ day $(\sim 0.017 \mathrm{mg} / \mathrm{kg} /$ day $)$ for 3 months resulted in a $30 \%$ to $40 \%$ decrease in phosphorylated tau.

In humans, davunetide intranasal (AL-108) has been studied for the treatment of amnestic MCI. The study was a randomized, double-blind, placebo-controlled, parallel group study. The effect of davunetide $5 \mathrm{mg}$ once daily and $15 \mathrm{mg}$ twice daily compared to placebo was evaluated in several tests of cognitive function. In that study, 144 subjects were randomized and 125 subjects completed the study. Subjects treated with davunetide $15 \mathrm{mg}$ twice daily demonstrated a general pattern of improvement in cognitive tests that primarily assessed attention and working memory function. Both doses of davunetide were safe and well tolerated. Headache and nasopharyngeal symptoms were the most commonly reported adverse events [131]. These studies place tau and tauopathies at central stage for further understanding of neurodegenerative diseases and the development of neuroprotective drugs.

Following our discovery of NAP (davunetide, [94]) we have suggested that NAP (davunetide) affects microtubule stability thereby providing neuroprotection $[132,133]$. Our recent studies extended the breadth of NAP (davunetide) application to show that it protected against cognitive dysfunction in a schizophrenia model of microtubule deficiency [134]. Importantly, clinical studies in schizophrenia patients suffering from cognitive impairment performed by TURNS (Treatment Units for Research on 
Neurocognition and Schizophrenia) in collaboration with Allon Therapeutics Inc. (www.allontherapeutics.com) showed protection of functional capacity (activities of daily living) and protection of brain function (magnetic resonance spectroscopy measurements of $\mathrm{N}$-acetyl aspartate) in the treated patients (Javitt et al., in preparation).

Based on the animal translational studies and the human clinical efficacy, davunetide is now poised for further clinical studies in PSP, an orphan indication (Allon Therapeutics, Inc.).

Paclitaxel and related compounds have been suggested to act also in protecting microtubules, however, bioavailability, brain specificity and the potential irreversibility of their action suggests that more work is required prior to paclitaxel-like neuroprotective drug candidate [135]. A drug candidate in a similar stage of development to davunetide is rember (methylene blue) that was featured in several AD meetings as per $[104,136]$.

In the preclinical stage, a phenylthiazolyl-hydrazide (PTH) compound was suggested as a possible hit in terms of inhibition of tau aggregation and the core of the PTHs crucial for activity was identified, thus representing a putative lead structure [137]. Recently, quantitative highthroughput screening (qHTS) of approximately 292000 compounds to identify drug-like inhibitors of tau assembly was developed. The fibrillization of a truncated tau fragment that contains four MT-binding domains was monitored in an assay that employed complementary thioflavin $\mathrm{T}$ fluorescence and fluorescence polarization methods. Previously described classes of inhibitors as well as new scaffolds were identified, including novel aminothienopyridazines (ATPZs). A number of ATPZ analogues were synthesized, and structure-activity relationships were defined. Further characterization of representative ATPZ compounds showed they do not interfere with tau-mediated MT assembly, and they are significantly more effective at preventing the fibrillization of tau than the Abeta(1-42) peptide which forms AD senile plaques. Thus, the ATPZ molecules are suggested for further development [138]. As a follow-up on these publications, AstraZeneca and The University of Pennsylvania recently announced a new collaborative research agreement that initially will focus on generating new $\mathrm{AD}$ drug candidates for the clinical development pipeline (http://www.astrazeneca.com/re search/?itemId=8876304).

Various tau aggregation inhibitory molecules were recently reviewed [104] also taking into consideration that the cellular environment affects tau aggregation. In this respect, it has been suggested that tau fragments across the lysosomal membrane promote formation of tau oligomers at the surface of these organelles which may act as precursors of aggregation and interfere with lysosomal functioning [139].

Other aspects of tau-related future therapeutics involve targeting tau hyperphosphorylation [140] with inhibitors of the key tau phosphorylating enzymes such as Cdk5/p25 kinase [141], GSK-3 inhibitors, such as lithium [142] or peptide inhibitors [143] and possible enhancement of protein phosphatase-2A (PP-2A) [144]. Other kinases implicated in tau phosphorylation include CK1, PK1, MARK, and the stress associated kinases, p38MAPK and JNK [140]. ATP competitive inhibitors may present potent drug candidates, but may also have undesirable side effects [106].

Regarding lithium, it is currently in clinical trials in PSP and CBD (http://clinicaltrials.gov/ct2/show/NCT00703677? term=lithium\&rank $=6$ ) and was tested in Alzheimer's disease patients (http://clinicaltrials.gov/ct2/show/NCT00088387? term $=$ lithium + alzheimer $\% 27 \mathrm{~s}+$ disease\&rank=1).

NP12 $\left(\right.$ Nypta $\left.^{\circledR}\right)$, a GSK-3 inhibitor [145], that we have reviewed in our paper "Looking for novel ways to treat the hallmarks of Alzheimer's disease" as microtubule related drug candidate [105] is a potent thiadiazolidinone derivative, that when injected into the rat hippocampus dramatically reduces kainic acid-induced inflammation, as measured by edema formation using $\mathrm{T}_{2}$-weighted magnetic
Table 1 Drug candidates

Other drug candidates of similar (or different) categories as well as innovative approaches are described in the text

\begin{tabular}{ll}
\hline Drug candidate & Activity \\
\hline Davunetide (NAP) & $\begin{array}{c}\text { Microtubule protection: preventing tau hyperphosphorylation } \\
\text { and tau aggregate formation and providing neuro-glial } \\
\text { protection }\end{array}$ \\
$\begin{array}{l}\text { Aminothienopyridazines (ATPZs) } \\
\text { Rember (methylene blue) and derivatives } \\
\text { GSK-3 inhibitors: }\end{array}$ & $\begin{array}{l}\text { Preventing tau aggregation } \\
\text { - lithium }\end{array}$ \\
$\begin{array}{l}\text { Ras-12 (Nypta }{ }^{\circledR} \text { ) } \\
\text { Immunotherapy }\end{array}$ & $\begin{array}{l}\text { Preventing tau phosphorylation } \\
\text { Neuroprotection }\end{array}$ \\
& $\begin{array}{c}\text { Anti-tau antibodies Potential personalized medicine - } \\
\text { future potential for targeting of specific mutations }\end{array}$ \\
\hline
\end{tabular}


resonance imaging and glial activation and has a neuroprotective effect in the damaged areas of the hippocampus [146].

NP-12 (Nypta ${ }^{\circledR}$ ), is claimed to be the first non ATP competitive inhibitor of GSK3, has been already administered to $>140$ healthy volunteers to date, as presented at the International Conference on Alzheimer's Disease (ICAD) in 2008. NP-12 is developed by Noscira (formerly Neuropharma, S.A.). Updates are available on the company website: "The first Phase II trial for Alzheimer's was approved in the last quarter of 2008; 30 patients have already been treated, and the results are being processed. Noscira expects the first Phase II clinical trial in PSP to begin in 2009."

Regarding kinase inhibition, internet search of SAR502250 revealed the patent application: WO/2009/035159 also including MITSUBISHI TANABE PHARMA CORPORATION in the applicants. The patent abstract describes a compound represented by a formula that is disclosed or a pharmaceutically acceptable salt thereof: which is used for preventive and/or therapeutic treatment of a disease caused by abnormal activity of tau protein kinase 1 such as a neurodegenerative diseases (e.g. Alzheimer disease) (http://www.wipo.int/pctdb/en/wo.jsp?WO=2009035159). Furthermore, SRN-003-556 was described as an inhibitor of tau hyperphosphorylation that prevents severe motor impairments in tau transgenic mice [147].

Brunden et al., also review the possibility of increased tau degradation as a therapeutic target also looking at hsp90 [148] as well as macroautophagy [139]. Neuroprotection is another approach to another disease associated with tau deregulation, A clinical trial with patients with Multiple System Atrophy (MSA), a disease with tau inclusions [149] and with parkinsonism is currently ongoing (http://clinical trials.gov/ct2/show/NCT00977665).

Another approach to clearing tau aggregates has been tau immunotherapy [150, 151]; this approach is still in the preclinical stage, showing potential promise in animal studies. Yet, another approach to the regulation of tau could be specific inhibition of synthesis, when this seems to lead to accumulation as well as addressing specific tau mutations (please see above and as described in http://www. alzforum.org/res/com/mut/tau/table1.asp). When RNA silencing and targeted in vivo mutagenesis further develop to potential candidate drugs, this would be an interesting avenue to follow. Finally, given the preponderance of 4 repeat (4R) tubulin binding domain tau in the neurodegenerative brain, drugs that target enhancement in the expression of the $3 \mathrm{R}$ tau to restore homeostasis are highly desirable, however, keeping in mind that the homeostasis between the $3 R$ and $4 R$ tau isoforms is important and that $3 \mathrm{R}$ tau has been associated with the pathology of Pick's disease $[33,65]$.
Additional reading on the subject can be found is several reviews including, but not limited to the following literature citations $[106,152]$ and including insights to the selection of the patient populations [153], some of the drug candidates outlined above are summarized in Table 1.

\section{Future outlook}

In terms of prediction, the tau mutations, amyloid precursor protein (APP) mutations, presenilin mutations and Down's syndrome predict tauopathy. Single nucleotide polymorphism (SNP) signatures may also contribute to disease susceptibility and progression. Furthermore, the tau gene haplotype contributes to susceptibility as well as additional risk genes like apoliprotein E4. Thus, genetic profiling will address prediction and provide for future diagnosis.

A very interesting facet of these diseases is the late onset; it is also possible that the initial progress is slower until it reaches a point of no return and is accelerated, perhaps due to accumulations of stress signals. In terms of diagnosis, one way is to follow-up plasma/blood and CSF samples of family members - carriers of mutations, heterozygous and non-carriers for tau abnormalities, changes in concentration, changes in degree of phosphorylation and truncation to address disease progression and potential preventative measures.

Personalized medicine in this respect will include customized immunotherapy as well as gene therapy, shutting down the mutated gene and introducing the healthy gene, using most advanced molecular genetic tools. Personalized treatment will stem from knowledge of the specific mutation, alteration in gene expression and posttranslational processing, toward a brighter future.

Acknowledgements I serve as the Chief Scientific Officer of Allon Therapeutics Inc. (www.allontherapeutics.com) and I am grateful to the Allon Therapeutics team for valuable input. Studies were supported in part by Allon Therapeutics Inc. and A.M.N Foundation.

At Tel Aviv University I serve as the incumbent of the Lily and Avraham Gildor Chair for the Investigation of growth Factors, the Director of the Adams Super Center for Brain Studies, the LevieEdersheim-Gitter fMRI Institute and the Dr. Diana and Zelman Elton (Elbaun) Laboratory for Molecular Neuroendocrinology. I also serve as the President of the Israel Society for Neuroscience.

\section{References}

1. Goedert M, Crowther RA, Spillantini MG. Tau mutations cause frontotemporal dementias. Neuron. 1998;21:955-8.

2. Gozes I, Littauer UZ. Tubulin microheterogeneity increases with rat brain maturation. Nature. 1978;276:411-3.

3. Gozes I, Sweadner KJ. Multiple tubulin forms are expressed by a single neurone. Nature. 1981;294:477-80. 
4. Gozes I, Saya D, Littauer UZ. Tubulin microheterogeneity in neuroblastoma and glioma cell lines differs from that of the brain. Brain Res. 1979;171:171-5.

5. Tischfield MA, Baris HN, Wu C, Rudolph G, Van Maldergem L, $\mathrm{He} \mathrm{W}$, et al. Human tubb3 mutations perturb microtubule dynamics, kinesin interactions, and axon guidance. Cell. 2010;140:74-87.

6. Cleveland DW, Hwo SY, Kirschner MW. Purification of tau, a microtubule-associated protein that induces assembly of microtubules from purified tubulin. J Mol Biol. 1977;116: 207-25.

7. Witman GB, Cleveland DW, Weingarten MD, Kirschner MW. Tubulin requires tau for growth onto microtubule initiating sites. Proc Natl Acad Sci USA. 1976;73:4070-4.

8. Bernhardt R, Matus A. Light and electron microscopic studies of the distribution of microtubule-associated protein 2 in rat brain: a difference between dendritic and axonal cytoskeletons. J Comp Neurol. 1984;226:203-21.

9. Weingarten MD, Lockwood AH, Hwo SY, Kirschner MW. A protein factor essential for microtubule assembly. Proc Natl Acad Sci USA. 1975;72:1858-62.

10. Cleveland DW, Hwo SY, Kirschner MW. Physical and chemical properties of purified tau factor and the role of tau in microtubule assembly. J Mol Biol. 1977;116:227-47.

11. Drubin DG, Caput D, Kirschner MW. Studies on the expression of the microtubule-associated protein, tau, during mouse brain development, with newly isolated complementary DNA probes. J Cell Biol. 1984;98:1090-7.

12. Ebneth A, Godemann R, Stamer K, Illenberger S, Trinczek B, Mandelkow E. Overexpression of tau protein inhibits kinesindependent trafficking of vesicles, mitochondria, and endoplasmic reticulum: implications for alzheimer's disease. J Cell Biol. 1998;143:777-94

13. Stamer K, Vogel R, Thies E, Mandelkow E, Mandelkow EM. Tau blocks traffic of organelles, neurofilaments, and app vesicles in neurons and enhances oxidative stress. J Cell Biol. 2002;156: 1051-63.

14. Gozes I. Tubulin in the nervous system. Neurochem Int. 1982;4:101-20.

15. Goedert M, Spillantini MG, Jakes R, Rutherford D, Crowther RA. Multiple isoforms of human microtubule-associated protein tau: sequences and localization in neurofibrillary tangles of alzheimer's disease. Neuron. 1989;3:519-26.

16. Himmler A, Drechsel D, Kirschner MW, Martin Jr DW. Tau consists of a set of proteins with repeated c-terminal microtubule-binding domains and variable n-terminal domains. Mol Cell Biol. 1989;9:1381-8.

17. Stoothoff W, Jones PB, Spires-Jones TL, Joyner D, Chhabra E, Bercury K, et al. Differential effect of three-repeat and fourrepeat tau on mitochondrial axonal transport. J Neurochem. 2009;111:417-27.

18. Shemesh OA, Erez H, Ginzburg I, Spira ME. Tau-induced traffic jams reflect organelles accumulation at points of microtubule polar mismatching. Traffic. 2008;9:458-71.

19. Gozes I. Tau pathology and future therapeutics. Curr Alzheimer Res. 2010 (in press).

20. Ballatore C, Lee VM, Trojanowski JQ. Tau-mediated neurodegeneration in alzheimer's disease and related disorders. Nat Rev Neurosci. 2007;8:663-72.

21. Grundke-Iqbal I, Iqbal K, Quinlan M, Tung YC, Zaidi MS, Wisniewski HM. Microtubule-associated protein tau. A component of alzheimer paired helical filaments. J Biol Chem. 1986;261:6084-9.

22. Delacourte A, Defossez A. Alzheimer's disease: tau proteins, the promoting factors of microtubule assembly, are major components of paired helical filaments. J Neurol Sci. 1986;76:173-86.
23. Wood JG, Mirra SS, Pollock NJ, Binder LI. Neurofibrillary tangles of alzheimer disease share antigenic determinants with the axonal microtubule-associated protein tau (tau). Proc Natl Acad Sci USA. 1986;83:4040-3.

24. Kosik KS, Joachim CL, Selkoe DJ. Microtubule-associated protein tau (tau) is a major antigenic component of paired helical filaments in alzheimer disease. Proc Natl Acad Sci USA. 1986;83:4044-8.

25. Nukina N, Ihara Y. One of the antigenic determinants of paired helical filaments is related to tau protein. J Biochem (Tokyo). 1986;99:1541-4.

26. Goedert M, Wischik CM, Crowther RA, Walker JE, Klug A. Cloning and sequencing of the cdna encoding a core protein of the paired helical filament of alzheimer disease: identification as the microtubule-associated protein tau. Proc Natl Acad Sci USA. 1988;85:4051-5.

27. Wischik CM, Novak M, Thogersen HC, Edwards PC, Runswick MJ, Jakes R, et al. Isolation of a fragment of tau derived from the core of the paired helical filament of alzheimer disease. Proc Natl Acad Sci USA. 1988;85:4506-10.

28. Kidd M. Paired helical filaments in electron microscopy of alzheimer's disease. Nature. 1963;197:192-3.

29. Kidd M. Alzheimer's disease - an electron microscopical study. Brain. 1964;87:307-20.

30. Wisniewski HM, Narang HK, Terry RD. Neurofibrillary tangles of paired helical filaments. J Neurol Sci. 1976;27:173-81.

31. Crowther RA, Wischik CM. Image reconstruction of the alzheimer paired helical filament. EMBO J. 1985;4:3661-5.

32. Gozes I, Schmitt H, Littauer UZ. Translation in vitro of rat brain messenger rna coding for tubulin and actin. Proc Natl Acad Sci USA. $1975 ; 72: 701-5$.

33. Robert M, Mathuranath PS. Tau and tauopathies. Neurol India. 2007;55:11-6

34. Hutton M, Lendon CL, Rizzu P, Baker M, Froelich S, Houlden $\mathrm{H}$, et al. Association of missense and $5^{\prime}$-splice-site mutations in tau with the inherited dementia ftdp-17. Nature. 1998;393:702-5.

35. Poorkaj P, Bird TD, Wijsman E, Nemens E, Garruto RM, Anderson $\mathrm{L}$, et al. Tau is a candidate gene for chromosome 17 frontotemporal dementia. Ann Neurol. 1998;43:815-25.

36. Spillantini MG, Murrell JR, Goedert M, Farlow MR, Klug A, Ghetti B. Mutation in the tau gene in familial multiple system tauopathy with presenile dementia. Proc Natl Acad Sci USA. 1998;95:7737-41.

37. Spillantini MG, Crowther RA, Kamphorst W, Heutink P, van Swieten JC. Tau pathology in two dutch families with mutations in the microtubule-binding region of tau. Am J Pathol. 1998;153:1359-63.

38. Grundke-Iqbal I, Iqbal K, Tung YC, Quinlan M, Wisniewski HM, Binder LI. Abnormal phosphorylation of the microtubuleassociated protein tau (tau) in alzheimer cytoskeletal pathology. Proc Natl Acad Sci USA. 1986;83:4913-7.

39. Ihara Y, Nukina N, Miura R, Ogawara M. Phosphorylated tau protein is integrated into paired helical filaments in alzheimer's disease. J Biochem (Tokyo). 1986;99:1807-10.

40. Trojanowski JQ, Lee VM. Phosphorylation of paired helical filament tau in alzheimer's disease neurofibrillary lesions: focusing on phosphatases. FASEB J. 1995;9:1570-6.

41. Liu F, Iqbal K, Grundke-Iqbal I, Hart GW, Gong CX. Oglcnacylation regulates phosphorylation of tau: a mechanism involved in alzheimer's disease. Proc Natl Acad Sci USA. 2004;101:10804-9.

42. Lee G, Thangavel R, Sharma VM, Litersky JM, Bhaskar K, Fang $\mathrm{SM}$, et al. Phosphorylation of tau by fyn: implications for alzheimer's disease. J Neurosci. 2004;24:2304-12.

43. Gong CX, Liu F, Grundke-Iqbal I, Iqbal K. Post-translational modifications of tau protein in alzheimer's disease. J Neural Transm. 2005;112:813-38. 
44. Gordon-Krajcer W, Yang L, Ksiezak-Reding H. Conformation of paired helical filaments blocks dephosphorylation of epitopes shared with fetal tau except ser199/202 and ser202/thr205. Brain Res. 2000;856:163-75.

45. Hernandez F, Lucas JJ, Cuadros R, Avila J. Gsk-3 dependent phosphoepitopes recognized by phf- 1 and at 8 antibodies are present in different tau isoforms. Neurobiol Aging. 2003;24:1087-94.

46. Terwel D, Dewachter I, Van Leuven F. Axonal transport, tau protein, and neurodegeneration in alzheimer's disease. Neuromolecular Med. 2002;2:151-65.

47. Drechsel DN, Hyman AA, Cobb MH, Kirschner MW. Modulation of the dynamic instability of tubulin assembly by the microtubuleassociated protein tau. Mol Biol Cell. 1992;3:1141-54.

48. Bramblett GT, Goedert M, Jakes R, Merrick SE, Trojanowski JQ, Lee VM. Abnormal tau phosphorylation at ser396 in alzheimer's disease recapitulates development and contributes to reduced microtubule binding. Neuron. 1993;10:1089-99.

49. Yoshida H, Ihara Y. Tau in paired helical filaments is functionally distinct from fetal tau: assembly incompetence of paired helical filament-tau. J Neurochem. 1993;61:1183-6.

50. Biernat J, Gustke N, Drewes G, Mandelkow EM, Mandelkow E. Phosphorylation of ser262 strongly reduces binding of tau to microtubules: distinction between phf-like immunoreactivity and microtubule binding. Neuron. 1993;11:153-63.

51. Jameson L, Frey T, Zeeberg B, Dalldorf F, Caplow M. Inhibition of microtubule assembly by phosphorylation of microtubuleassociated proteins. Biochemistry. 1980;19:2472-9.

52. Lindwall G, Cole RD. Phosphorylation affects the ability of tau protein to promote microtubule assembly. J Biol Chem. 1984;259:5301-5.

53. Alonso A, Zaidi T, Novak M, Grundke-Iqbal I, Iqbal K. Hyperphosphorylation induces self-assembly of tau into tangles of paired helical filaments/straight filaments. Proc Natl Acad Sci USA. 2001;98:6923-8.

54. Haase C, Stieler JT, Arendt T, Holzer M. Pseudophosphorylation of tau protein alters its ability for self-aggregation. J Neurochem. 2004;88:1509-20.

55. Litersky JM, Johnson GV. Phosphorylation by camp-dependent protein kinase inhibits the degradation of tau by calpain. J Biol Chem. 1992;267:1563-8.

56. Qian W, Shi J, Yin X, Iqbal K, Grundke-Iqbal I, Gong CX, et al. Pp2a regulates tau phosphorylation directly and also indirectly via activating gsk-3beta. $\mathrm{J}$ Alzheimers Dis. 2010;19: 1221-9.

57. Tremblay MA, Acker CM, Davies P. Tau phosphorylated at tyrosine 394 is found in alzheimer's disease tangles and can be a product of the abl-related kinase, arg. J Alzheimers Dis. 2010;19: 721-33.

58. Donnelly MP, Paschou P, Grigorenko E, Gurwitz D, Mehdi SQ, Kajuna SL, et al. The distribution and most recent common ancestor of the 17q21 inversion in humans. Am J Hum Genet. 2010;86:161-71.

59. Baker M, Litvan I, Houlden H, Adamson J, Dickson D, PerezTur J, et al. Association of an extended haplotype in the tau gene with progressive supranuclear palsy. Hum Mol Genet. 1999;8: $711-5$.

60. Pittman AM, Myers AJ, Duckworth J, Bryden L, Hanson M, Abou-Sleiman P, et al. The structure of the tau haplotype in controls and in progressive supranuclear palsy. Hum Mol Genet. 2004; 13:1267-74.

61. Caffrey TM, Wade-Martins R. Functional mapt haplotypes: bridging the gap between genotype and neuropathology. Neurobiol Dis. 2007;27:1-10.

62. Pittman AM, Myers AJ, Abou-Sleiman P, Fung HC, Kaleem M, Marlowe L, et al. Linkage disequilibrium fine mapping and haplotype association analysis of the tau gene in progressive supranuclear palsy and corticobasal degeneration. J Med Genet. 2005;42:837-46.

63. Di Maria E, Cammarata S, Parodi MI, Borghi R, Benussi L, Galli M, et al. The h1 haplotype of the tau gene (mapt) is associated with mild cognitive impairment. J Alzheimers Dis. 2010;19:909-14.

64. Borroni B, Grassi M, Agosti C, Premi E, Archetti S, Alberici A, et al. Establishing short-term prognosis in frontotemporal lobar degeneration spectrum: role of genetic background and clinical phenotype. Neurobiol Aging. 2010;31:270-9.

65. Desai AK, Chand P. Tau-based therapies for alzheimer's disease: wave of the future? Primary Psychiatry. 2009;16:40-6.

66. Hauw JJ, Daniel SE, Dickson D, Horoupian DS, Jellinger K, Lantos PL, et al. Preliminary ninds neuropathologic criteria for steele-richardson-olszewski syndrome (progressive supranuclear palsy). Neurology. 1994;44:2015-9.

67. Dickson DW, Rademakers R, Hutton ML. Progressive supranuclear palsy: pathology and genetics. Brain Pathol. 2007;17: 74-82.

68. Spillantini MG, Bird TD, Ghetti B. Frontotemporal dementia and parkinsonism linked to chromosome 17: a new group of tauopathies. Brain Pathol. 1998;8:387-402.

69. Litvan I, Agid Y, Jankovic J, Goetz C, Brandel JP, Lai EC, et al. Accuracy of clinical criteria for the diagnosis of progressive supranuclear palsy (steele-richardson-olszewski syndrome). Neurology. 1996;46:922-30.

70. Pillon B, Dubois B, Ploska A, Agid Y. Severity and specificity of cognitive impairment in alzheimer's, huntington's, and parkinson's diseases and progressive supranuclear palsy. Neurology. 1991;41:634-43.

71. Litvan I, Agid Y, Calne D, Campbell G, Dubois B, Duvoisin RC, et al. Clinical research criteria for the diagnosis of progressive supranuclear palsy (steele-richardson-olszewski syndrome): report of the ninds-spsp international workshop. Neurology. 1996;47:1-9.

72. Schrag A, Ben-Shlomo Y, Quinn NP. Prevalence of progressive supranuclear palsy and multiple system atrophy: a crosssectional study. Lancet. 1999;354:1771-5.

73. Testa D, Monza D, Ferrarini M, Soliveri P, Girotti F, Filippini G. Comparison of natural histories of progressive supranuclear palsy and multiple system atrophy. Neurol Sci. 2001;22:24751 .

74. Golbe LI, Ohman-Strickland PA. A clinical rating scale for progressive supranuclear palsy. Brain. 2007;130:1552-65.

75. Paviour DC, Price SL, Lees AJ, Fox NC. Mri derived brain atrophy in psp and msa-p. Determining sample size to detect treatment effects. J Neurol. 2007;254:478-81.

76. Whitwell JL, Jack Jr CR, Parisi JE, Knopman DS, Boeve BF, Petersen RC, et al. Rates of cerebral atrophy differ in different degenerative pathologies. Brain. 2007;130:1148-58.

77. Cordato NJ, Duggins AJ, Halliday GM, Morris JG, Pantelis C. Clinical deficits correlate with regional cerebral atrophy in progressive supranuclear palsy. Brain. 2005;128:1259-66.

78. Boxer AL, Geschwind MD, Belfor N, Gorno-Tempini ML, Schauer GF, Miller BL, et al. Patterns of brain atrophy that differentiate corticobasal degeneration syndrome from progressive supranuclear palsy. Arch Neurol. 2006;63:81-6.

79. Guillozet-Bongaarts AL, Glajch KE, Libson EG, Cahill ME, Bigio E, Berry RW, et al. Phosphorylation and cleavage of tau in non-ad tauopathies. Acta Neuropathol. 2007;113:513-20.

80. Wang Y, Gao L, Tse SW, Andreadis A. Heterogeneous nuclear ribonucleoprotein e3 modestly activates splicing of tau exon 10 via its proximal downstream intron, a hotspot for frontotemporal dementia mutations. Gene. 2010;451:23-31.

81. Suh J, Im DS, Moon GJ, Ryu KS, de Silva R, Choi IS, et al. Hypoxic ischemia and proteasome dysfunction alter tau 
isoform ratio by inhibiting exon 10 splicing. J Neurochem. 2010;114:160-170

82. Walhovd KB, Fjell AM, Brewer J, McEvoy LK, FennemaNotestine C, Hagler Jr DJ, et al. Combining $\mathrm{mr}$ imaging, positron-emission tomography, and csf biomarkers in the diagnosis and prognosis of alzheimer disease. AJNR Am J Neuroradiol. 2010;31:347-54.

83. Shaw LM, Vanderstichele H, Knapik-Czajka M, Clark CM, Aisen PS, Petersen RC, et al. Cerebrospinal fluid biomarker signature in alzheimer's disease neuroimaging initiative subjects. Ann Neurol. 2009;65:403-13.

84. Buerger K, Frisoni G, Uspenskaya O, Ewers M, Zetterberg H, Geroldi C, et al. Validation of alzheimer's disease csf and plasma biological markers: the multicentre reliability study of the pilot european alzheimer's disease neuroimaging initiative (e-adni). Exp Gerontol. 2009;44:579-85.

85. Leow AD, Yanovsky I, Parikshak N, Hua X, Lee S, Toga AW, et al. Alzheimer's disease neuroimaging initiative: a one-year follow up study using tensor-based morphometry correlating degenerative rates, biomarkers and cognition. Neuroimage. 2009;45:645-55.

86. Jack Jr CR, Knopman DS, Jagust WJ, Shaw LM, Aisen PS, Weiner MW, et al. Hypothetical model of dynamic biomarkers of the alzheimer's pathological cascade. Lancet Neurol. 2010;9: 119-28.

87. Fjell AM, Walhovd KB, Fennema-Notestine C, McEvoy LK, Hagler DJ, Holland D, et al. Csf biomarkers in prediction of cerebral and clinical change in mild cognitive impairment and alzheimer's disease. J Neurosci. 2010;30:2088-101.

88. Stomrud E, Hansson O, Zetterberg H, Blennow K, Minthon L, Londos E. Correlation of longitudinal cerebrospinal fluid biomarkers with cognitive decline in healthy older adults. Arch Neurol. 2010;67:217-23.

89. Hanisch K, Soininen H, Alafuzoff I, Hoffmann R. Analysis of human tau in cerebrospinal fluid. J Proteome Res. 2010;9:147682.

90. Borroni B, Gardoni F, Parnetti L, Magno L, Malinverno M, Saggese $\mathrm{E}$, et al. Pattern of tau forms in csf is altered in progressive supranuclear palsy. Neurobiol Aging. 2009;30: 34-40.

91. Constantinescu R, Zetterberg H, Holmberg B, Rosengren L. Levels of brain related proteins in cerebrospinal fluid: an aid in the differential diagnosis of parkinsonian disorders. Parkinsonism Relat Disord. 2009;15:205-12.

92. Ray S, Britschgi M, Herbert C, Takeda-Uchimura Y, Boxer A, Blennow $\mathrm{K}$, et al. Classification and prediction of clinical alzheimer's diagnosis based on plasma signaling proteins. Nat Med. 2007;13:1359-62.

93. Braskie MN, Klunder AD, Hayashi KM, Protas H, Kepe V, Miller KJ, et al. Plaque and tangle imaging and cognition in normal aging and alzheimer's disease. Neurobiol Aging. 2008 doi:10.1016/j.neurobiology.2008.09.012.

94. Bassan M, Zamostiano R, Davidson A, Pinhasov A, Giladi E, Perl $\mathrm{O}$, et al. Complete sequence of a novel protein containing a femtomolar-activity-dependent neuroprotective peptide. J Neurochem. 1999;72:1283-93.

95. Zamostiano R, Pinhasov A, Gelber E, Steingart RA, Seroussi E, Giladi E, et al. Cloning and characterization of the human activity-dependent neuroprotective protein. J Biol Chem. 2001;276:708-14

96. Gozes I. Activity-dependent neuroprotective protein: from gene to drug candidate. Pharmacol Ther. 2007;114:146-54.

97. Pinhasov A, Mandel S, Torchinsky A, Giladi E, Pittel Z, Goldsweig AM, et al. Activity-dependent neuroprotective protein: a novel gene essential for brain formation. Brain Res Dev Brain Res. 2003;144:83-90.

98. Mandel S, Rechavi G, Gozes I. Activity-dependent neuroprotective protein (adnp) differentially interacts with chromatin to regulate genes essential for embryogenesis. Dev Biol. 2007;303:814-24.

99. Mandel S, Gozes I. Activity-dependent neuroprotective protein constitutes a novel element in the swi/snf chromatin remodeling complex. J Biol Chem. 2007;282:34448-56.

100. Vulih-Shultzman I, Pinhasov A, Mandel S, Grigoriadis N, Touloumi O, Pittel Z, et al. Activity-dependent neuroprotective protein snippet nap reduces tau hyperphosphorylation and enhances learning in a novel transgenic mouse model. J Pharmacol Exp Ther. 2007;323:438-49.

101. Braitch M, Kawabe K, Nyirenda M, Gilles LJ, Robins RA, Gran B, et al. Expression of activity-dependent neuroprotective protein in the immune system: possible functions and relevance to multiple sclerosis. Neuroimmunomodulation. 2009; 17:120-5.

102. Anderson JM, Patani R, Reynolds R, Nicholas R, Compston A, Spillantini MG, et al. Evidence for abnormal tau phosphorylation in early aggressive multiple sclerosis. Acta Neuropathol. 2009;117:583-9.

103. Gozes I. Tau as a drug target in alzheimer's disease. J Mol Neurosci. 2002;19:337-8.

104. Bulic B, Pickhardt M, Schmidt B, Mandelkow EM, Waldmann H, Mandelkow E. Development of tau aggregation inhibitors for alzheimer's disease. Angew Chem Int Ed Engl. 2009;48:1740-52.

105. Stewart AJ, Fox A, Morimoto BH, Gozes I. Looking for novel ways to treat the hallmarks of alzheimer's disease. Expert Opin Investig Drugs. 2007;16:1183-96.

106. Brunden KR, Trojanowski JQ, Lee VM. Advances in taufocused drug discovery for alzheimer's disease and related tauopathies. Nat Rev Drug Discov. 2009;8:783-93.

107. Paquet D, Bhat R, Sydow A, Mandelkow EM, Berg S, Hellberg $\mathrm{S}$, et al. A zebrafish model of tauopathy allows in vivo imaging of neuronal cell death and drug evaluation. J Clin Invest. 2009;119:1382-95.

108. Chatterjee S, Sang TK, Lawless GM, Jackson GR. Dissociation of tau toxicity and phosphorylation: role of gsk-3beta, mark and cdk5 in a drosophila model. Hum Mol Genet. 2009;18:164-77.

109. Gotz J, Ittner LM. Animal models of alzheimer's disease and frontotemporal dementia. Nat Rev Neurosci. 2008;9:532-44.

110. Ramsden M, Kotilinek L, Forster C, Paulson J, McGowan E, SantaCruz K, et al. Age-dependent neurofibrillary tangle formation, neuron loss, and memory impairment in a mouse model of human tauopathy (p3011). J Neurosci. 2005;25:10637-47.

111. Frost B, Diamond MI. Prion-like mechanisms in neurodegenerative diseases. Nat Rev Neurosci. 2010;11:155-9.

112. Sydow A, Mandelkow EM. 'prion-like' propagation of mouse and human tau aggregates in an inducible mouse model of tauopathy. Neurodegener Dis. 2010;7:28-31.

113. Kim W, Lee S, Jung C, Ahmed A, Lee G, Hall GF. Interneuronal transfer of human tau between lamprey central neurons in situ. J Alzheimers Dis. 2010;19:647-64.

114. Matrone MA, Whipple RA, Thompson K, Cho EH, Vitolo MI, Balzer EM, et al. Metastatic breast tumors express increased tau, which promotes microtentacle formation and the reattachment of detached breast tumor cells. Oncogene. 2010;29:3217-3227.

115. Gozes I, Divinsky I, Pilzer I, Fridkin M, Brenneman DE, Spier AD. From vasoactive intestinal peptide (vip) through activity-dependent neuroprotective protein (adnp) to nap: a view of neuroprotection and cell division. J Mol Neurosci. 2003;20: 315-22.

116. Gozes I, Morimoto BH, Tiong J, Fox AW, Sutherland K, Dangoor D, et al. Nap: research and development of a peptide derived from activity dependent neuroprotective protein. CNS Drug Rev. 2005;11:363-78.

117. Gozes I, Divinski I, Piltzer I. Nap and d-sal: neuroprotection against the beta amyloid peptide (1-42). BMC Neurosci. 2008;9 Suppl 3:S3. 
118. Steingart RA, Solomon B, Brenneman DE, Fridkin M, Gozes I. Vip and peptides related to activity-dependent neurotrophic factor protect pc12 cells against oxidative stress. J Mol Neurosci. 2000;15:137-45.

119. Zemlyak I, Sapolsky R, Gozes I. Nap protects against cytochrome $\mathrm{c}$ release: inhibition of the initiation of apoptosis. Eur $\mathrm{J}$ Pharmacol. 2009;618:9-14.

120. Smith-Swintosky VL, Gozes I, Brenneman DE, D'Andrea MR, Plata-Salaman CR. Activity-dependent neurotrophic factor-9 and nap promote neurite outgrowth in rat hippocampal and cortical cultures. J Mol Neurosci. 2005;25:225-38.

121. Pascual M, Guerri C. The peptide nap promotes neuronal growth and differentiation through extracellular signalregulated protein kinase and akt pathways, and protects neurons co-cultured with astrocytes damaged by ethanol. J Neurochem. 2007;103:557-68.

122. Jehle T, Dimitriu C, Auer S, Knoth R, Vidal-Sanz M, Gozes I, et al. The neuropeptide nap provides neuroprotection against retinal ganglion cell damage after retinal ischemia and optic nerve crush. Graefes Arch Clin Exp Ophthalmol. 2008;246:1255-63.

123. Chen S, Charness ME. Ethanol inhibits neuronal differentiation by disrupting activity-dependent neuroprotective protein signaling. Proc Natl Acad Sci USA. 2008;105:19962-7.

124. Quintana FJ, Zaltzman R, Fernandez-Montesinos R, Herrera JL, Gozes I, Cohen IR, et al. Nap, a peptide derived from the activity-dependent neuroprotective protein, modulates macrophage function. Ann NY Acad Sci. 2006;1070:500-6.

125. Shiryaev N, Jouroukhin Y, Giladi E, Polyzoidou E, Grigoriadis $\mathrm{NC}$, Rosenmann $\mathrm{H}$, et al. Nap protects memory, increases soluble tau and reduces tau hyperphosphorylation in a tauopathy model. Neurobiol Dis. 2009;34:381-8.

126. Rosenmann H, Grigoriadis N, Eldar-Levy H, Avital A, Rozenstein $\mathrm{L}$, Touloumi $\mathrm{O}$, et al. A novel transgenic mouse expressing double mutant tau driven by its natural promoter exhibits tauopathy characteristics. Exp Neurol. 2008;212:71-84.

127. Lee VM, Goedert M, Trojanowski JQ. Neurodegenerative tauopathies. Annu Rev Neurosci. 2001;24:1121-59.

128. Oddo S, Caccamo A, Shepherd JD, Murphy MP, Golde TE, Kayed R, et al. Triple-transgenic model of alzheimer's disease with plaques and tangles: intracellular abeta and synaptic dysfunction. Neuron. 2003;39:409-21.

129. Matsuoka Y, Gray AJ, Hirata-Fukae C, Minami SS, Waterhouse EG, Mattson MP, et al. Intranasal nap administration reduces accumulation of amyloid peptide and tau hyperphosphorylation in a transgenic mouse model of alzheimer's disease at early pathological stage. J Mol Neurosci. 2007;31:165-70.

130. Matsuoka Y, Jouroukhin Y, Gray AJ, Ma L, Hirata-Fukae C, Li $\mathrm{HF}$, et al. A neuronal microtubule-interacting agent, napvsipq, reduces tau pathology and enhances cognitive function in a mouse model of alzheimer's disease. J Pharmacol Exp Ther. 2008;325:146-53.

131. Gozes I, Stewart A, Morimoto B, Fox A, Sutherland K, Schmeche D. Addressing alzheimer's disease tangles: from nap to al-108. Curr Alzheimer Res. 2009;6:455-60.

132. Divinski I, Mittelman L, Gozes I. A femtomolar acting octapeptide interacts with tubulin and protects astrocytes against zinc intoxication. J Biol Chem. 2004;279:28531-8.

133. Divinski I, Holtser-Cochav M, Vulih-Schultzman I, Steingart RA, Gozes I. Peptide neuroprotection through specific interaction with brain tubulin. J Neurochem. 2006;98:973-84.

134. Merenlender-Wagner A, Pikman R, Giladi E, Andrieux A, Gozes I. Nap (davunetide) enhances cognitive behavior in the stop heterozygous mouse - a microtubule-deficient model of schizophrenia. Peptides. 2010;31:1368-73.
135. Butler D, Bendiske J, Michaelis ML, Karanian DA, Bahr BA. Microtubule-stabilizing agent prevents protein accumulationinduced loss of synaptic markers. Eur J Pharmacol. 2007;562:20-7.

136. Wischik CM, Edwards PC, Lai RY, Roth M, Harrington CR. Selective inhibition of alzheimer disease-like tau aggregation by phenothiazines. Proc Natl Acad Sci USA. 1996;93: 11213-8.

137. Pickhardt M, Larbig G, Khlistunova I, Coksezen A, Meyer B, Mandelkow EM, et al. Phenylthiazolyl-hydrazide and its derivatives are potent inhibitors of tau aggregation and toxicity in vitro and in cells. Biochemistry. 2007;46:10016-23.

138. Crowe A, Huang W, Ballatore C, Johnson RL, Hogan AM, Huang $\mathrm{R}$, et al. Identification of aminothienopyridazine inhibitors of tau assembly by quantitative high-throughput screening. Biochemistry. 2009;48:7732-45.

139. Wang Y, Martinez-Vicente M, Kruger U, Kaushik S, Wong E, Mandelkow EM, et al. Tau fragmentation, aggregation and clearance: the dual role of lysosomal processing. Hum Mol Genet. 2009;18:4153-70.

140. Hanger DP, Anderton BH, Noble W. Tau phosphorylation: the therapeutic challenge for neurodegenerative disease. Trends Mol Med. 2009;15:112-9.

141. Liu M, Choi S, Cuny GD, Ding K, Dobson BC, Glicksman MA, et al. Kinetic studies of $\mathrm{cdk} 5 / \mathrm{p} 25$ kinase: phosphorylation of tau and complex inhibition by two prototype inhibitors. Biochemistry. 2008;47:8367-77.

142. Engel T, Goni-Oliver P, Gomez de Barreda E, Lucas JJ, Hernandez F, Avila J. Lithium, a potential protective drug in alzheimer's disease. Neurodegener Dis. 2008;5:247-9.

143. Eldar-Finkelman H, Eisenstein M. Peptide inhibitors targeting protein kinases. Curr Pharm Des. 2009;15:2463-70.

144. Iqbal K, Grundke-Iqbal I. Alzheimer neurofibrillary degeneration: significance, etiopathogenesis, therapeutics and prevention. J Cell Mol Med. 2008;12:38-55.

145. Martinez A, Perez DI. Gsk-3 inhibitors: a ray of hope for the treatment of alzheimer's disease? J Alzheimers Dis. 2008;15: 181-91.

146. Luna-Medina R, Cortes-Canteli M, Sanchez-Galiano S, MoralesGarcia JA, Martinez A, Santos A, et al. Np031112, a thiadiazolidinone compound, prevents inflammation and neurodegeneration under excitotoxic conditions: potential therapeutic role in brain disorders. J Neurosci. 2007;27:5766-76.

147. Le Corre S, Klafki HW, Plesnila N, Hubinger G, Obermeier A, Sahagun $\mathrm{H}$, et al. An inhibitor of tau hyperphosphorylation prevents severe motor impairments in tau transgenic mice. Proc Natl Acad Sci USA. 2006;103:9673-8.

148. Dickey CA, Koren J, Zhang YJ, Xu YF, Jinwal UK, Birnbaum $\mathrm{MJ}$, et al. Akt and chip coregulate tau degradation through coordinated interactions. Proc Natl Acad Sci USA. 2008;105: $3622-7$.

149. Takeda A, Arai N, Komori T, Iseki E, Kato S, Oda M. Tau immunoreactivity in glial cytoplasmic inclusions in multiple system atrophy. Neurosci Lett. 1997;234:63-6.

150. Sigurdsson EM. Tau-focused immunotherapy for alzheimer's disease and related tauopathies. Curr Alzheimer Res. 2009;6:446-50.

151. Rosenmann H, Meiner Z, Geylis V, Abramsky O, Steinitz M. Detection of circulating antibodies against tau protein in its unphosphorylated and in its neurofibrillary tangles-related phosphorylated state in alzheimer's disease and healthy subjects. Neurosci Lett. 2006;410:90-3.

152. Trojanowski JQ, Duff K, Fillit H, Koroshetz W, Kuret J, Murphy $\mathrm{D}$, et al. New directions for frontotemporal dementia drug discovery. Alzheimers Dement. 2008;4:89-93.

153. Iqbal K, Chohan MO, Grundke-Iqbal I. Stratification of patients is the way to go to develop neuroprotective/disease-modifying drugs for alzheimer's disease. J Alzheimers Dis. 2008;15:339-45. 